\title{
A rainfall loading response recorded at 300 meters depth: implications for geological weighing lysimeters
}

\author{
Marios Sophocleous ${ }^{1}$, Earl Bardsley ${ }^{2}$, and John Healey ${ }^{1}$ \\ ${ }^{1}$ Kansas Geological Survey, The University of Kansas, Lawrence, KS 66047, USA \\ ${ }^{2}$ Department of Earth Sciences, University of Waikato, Hamilton, New Zealand
}

Journal of Hydrology 2006, v.319, p.237-244

2web@waikato.ac.nz 


\begin{abstract}
Static pore water pressures in confined aquifers vary in response to ground surface loading changes, including precipitation and evaporation. Under certain hydrogeological conditions such aquifers can function as giant natural weighing lysimeters, referenced here as "geological weighing lysimeters". The extent of the land area "weighed" increases with aquifer depth and it is of interest to establish at what depth it is still possible to monitor surface water budgets. An $86 \mathrm{~mm}$ rainfall event produced a clear loading signal in a well in western Kansas at 300 meters depth. The loading effect is quantitatively consistent with elastic deformation induced by the rainfall mass and suggests that geological weighing lysimeters could operate at considerably greater depths, thereby monitoring water budgets over a significant land area.
\end{abstract}

Key words: water budget; geological weighing lysimeter; formation loading, Kansas. 


\section{Introduction}

Static pore water pressures in elastic confined aquifers may change measurably in response to ground surface loading. The change in pore water pressure is determined by the loading coefficient $c=1-b$, where $b$ is the static confined barometric efficiency [Jacob, 1940]. The loading efficiency can be regarded as a time-invariant constant characterizing aquifer response to ground surface loading, provided the confining aquitard is thick and has low diffusivity so that there is minimal leakage of water pressure changes [Rojstaczer, 1988; Roeloffs, 1996]. Confined aquifers in this situation can serve as giant natural weighing lysimeters for in situ monitoring of surface water budgets, subject to the additional condition that there are negligible dynamic effects influencing pore water pressures [van der Kamp and Maathuis, 1991; Bardsley and Campbell, 1994, 2000]. For convenience, such systems are referred to here as "geological weighing lysimeters". The term is used in this paper in the context of confined aquifer measurements only. However, the geological weighing lysimeter concept has also been applied to aquitard measurements as well [van der Kamp and Schmidt, 1997].

The focus of geological weighing lysimeters is toward the surface water budget rather than as a means of deducing geological formation elastic properties and deformation modes. In essence, the approach is pragmatic in that pore water pressure response is simply assumed consistent for all surface loading - whether due to atmospheric pressure changes or surface water storage changes. Once calibrated by atmospheric pressure data, the water mass loading changes appear after atmospheric pressure correction of recorded pore water pressures. Surface loading effects on confined units may include horizontal strain effects (Rojstaczer and Agnew, 1989) but this is of no particular consequence to the operation of a geological weighing lysimeter.

The unique feature of geological weighing lysimeters is their ability to give a spatial average of surface water budget changes over an extended land area. The size of the averaged area is difficult to quantify exactly but must increase with both aquifer transmissivity and depth below ground surface. Even aquitard-based measurements indicate that a 30-meter piezometer depth will result in an averaged ground surface monitored area in the order of hectares [van der Kamp and Schmidt, 1997].

It is of interest to establish recorded observations of surface loading effects at depth because this extends the potential operational range of geological weighing lysimeters and, by implication, the area of land surface monitored. Presently the greatest depth of an operational geological weighing lysimeter is 160 meters at a site in New Zealand [Bardsley and Campbell, 2000]. The maximum functioning depth may in fact be considerably greater because a general model suggests that surface load deformation 
penetrates to a depth approximately twice the length scale of the loaded area [Pagiatakis, 1990]. A significant rainfall event, for example, might extend a surface loading effect at least over several kilometers.

One approach to detecting deep loading would be to simply check for barometric effects in deep open wells, because the inverse barometric effect represents in part the effect of atmospheric ground surface loading. This is not entirely unambiguous, however, because some aquifer waters may accumulate gas bubbles which cause significant increases in pore water compressibility [Matsumoto and Roeloffs, 2003]. Open wells in such situations would display an apparent inverse barometric effect even when there was no transmission of surface loading through the confining layers. This potential problem can be avoided in open wells by checking for the effect of loading by ocean tides or rainfall events, which do not impact directly on the well water surface. Alternatively, deep wells could be sealed from the atmosphere and a check made for a positive water level response to ground surface atmospheric loading variations.

The loading signal of individual precipitation events is of particular interest from the geological weighing lysimeter viewpoint because this represents inputs to the surface water budget. Rainfall events appear to have been previously detected at 500 meters depth [Igarashi and Wakita, 1991] but the signal was poorly defined. Bardsley and Campbell [2000] reference the loading effect of a 40-mm rainfall event, detected at 240 meters below ground surface in a seismic monitoring network near Parkfield, California. We report in this short communication a rainfall loading response at almost 300 meters depth from a sealed well near WaKeeney, west-central Kansas. We believe this to be one of the clearest signals to date of rainfall loading at depth, suggesting that there is indeed scope for extension of geological weighing lysimeters to at least this depth and possibly considerably deeper.

\section{The WaKeeney well site and its environment}

The site of the WaKeeney monitoring well is in Trego County in west-central Kansas, approximately $7.6 \mathrm{~km}$ northwest of the town of WaKeeney (Fig. 1). The site lies within the High Plains physiographic province of western Kansas and is characterized by gently rolling uplands that are moderately dissected by smaller drainage ways. The WaKeeney area has a semiarid continental climate with low to moderate annual precipitation averaging around $550 \mathrm{~mm}$. Annual potential evaporation is high — the 2003 value (based on the (wind function-) modified Penman equation with alfalfa as a reference crop) was approximately $1900 \mathrm{~mm}$ (http://www.oznet.ksu.edu/wdl/). 


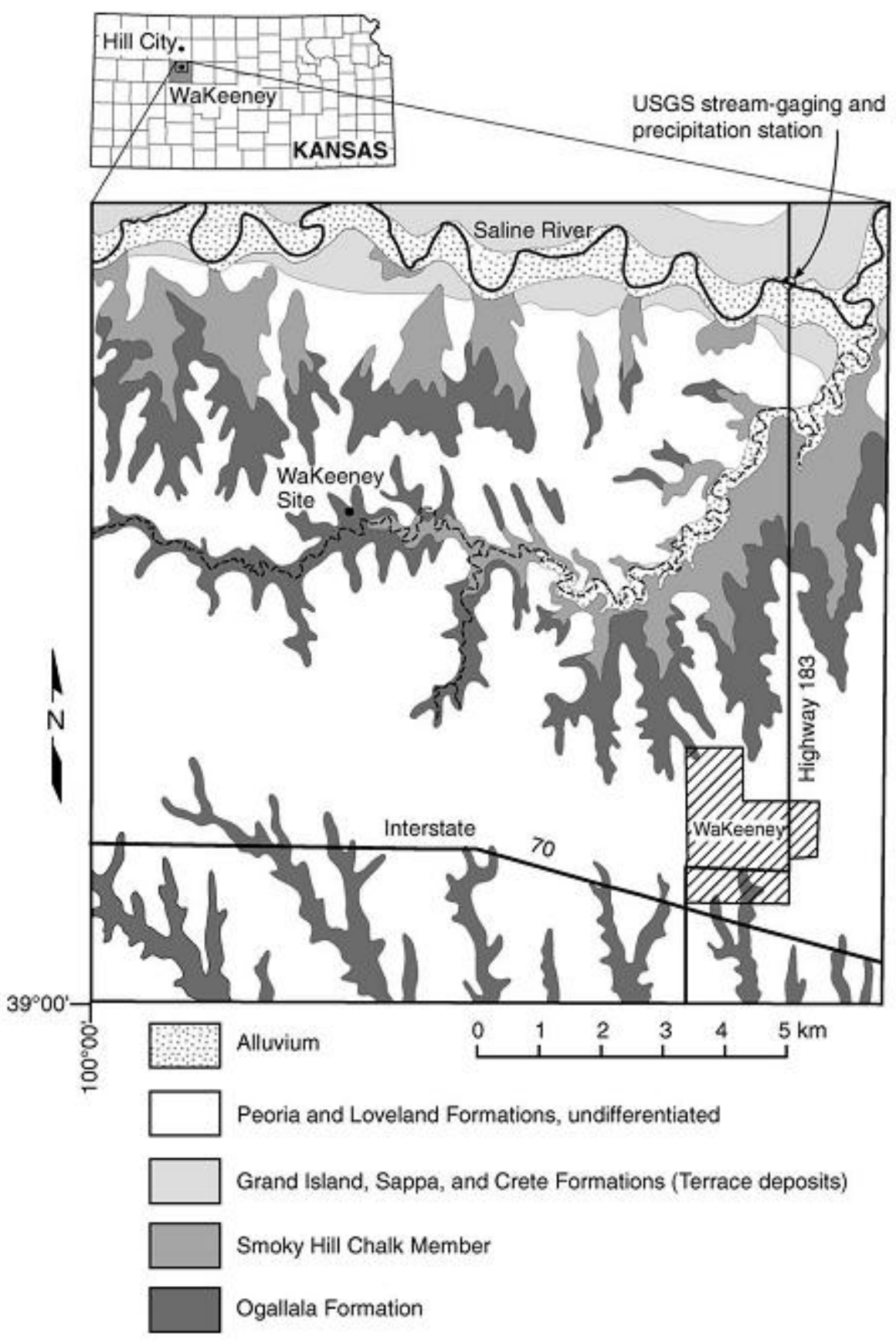

Figure 1. Location of the WaKeeney well site and area geology (modified from Hodson, 1965).

The rocks that crop out in the area are sedimentary in origin and range in age from Cretaceous to Holocene (Fig. 1; Hodson, 1965). A drilled section of the rock units at the site is given in Fig. 2, together with WaKeeney well-construction details and other relevant information. Alluvium of late Wisconsinan and Holocene age occurs along the principal streams and smaller valleys in the county. The Pleistocene Series is represented 
by unconsolidated deposits of both fluviatile and eolian origin. Thin eolian silts (loess) of late Pleistocene age cover a considerable part of Trego County and are shown as the Peoria and Loveland Formations undifferentiated in Fig. 1. The Ogallala Formation of Pliocene age unconformably overlies the Cretaceous rocks in much of the upland areas of the county and consists predominantly of sand, gravel, silt, and clay. The Ogallala Formation is the most widespread shallow water-bearing formation in Trego County, although its thickness is relatively small compared to further west.

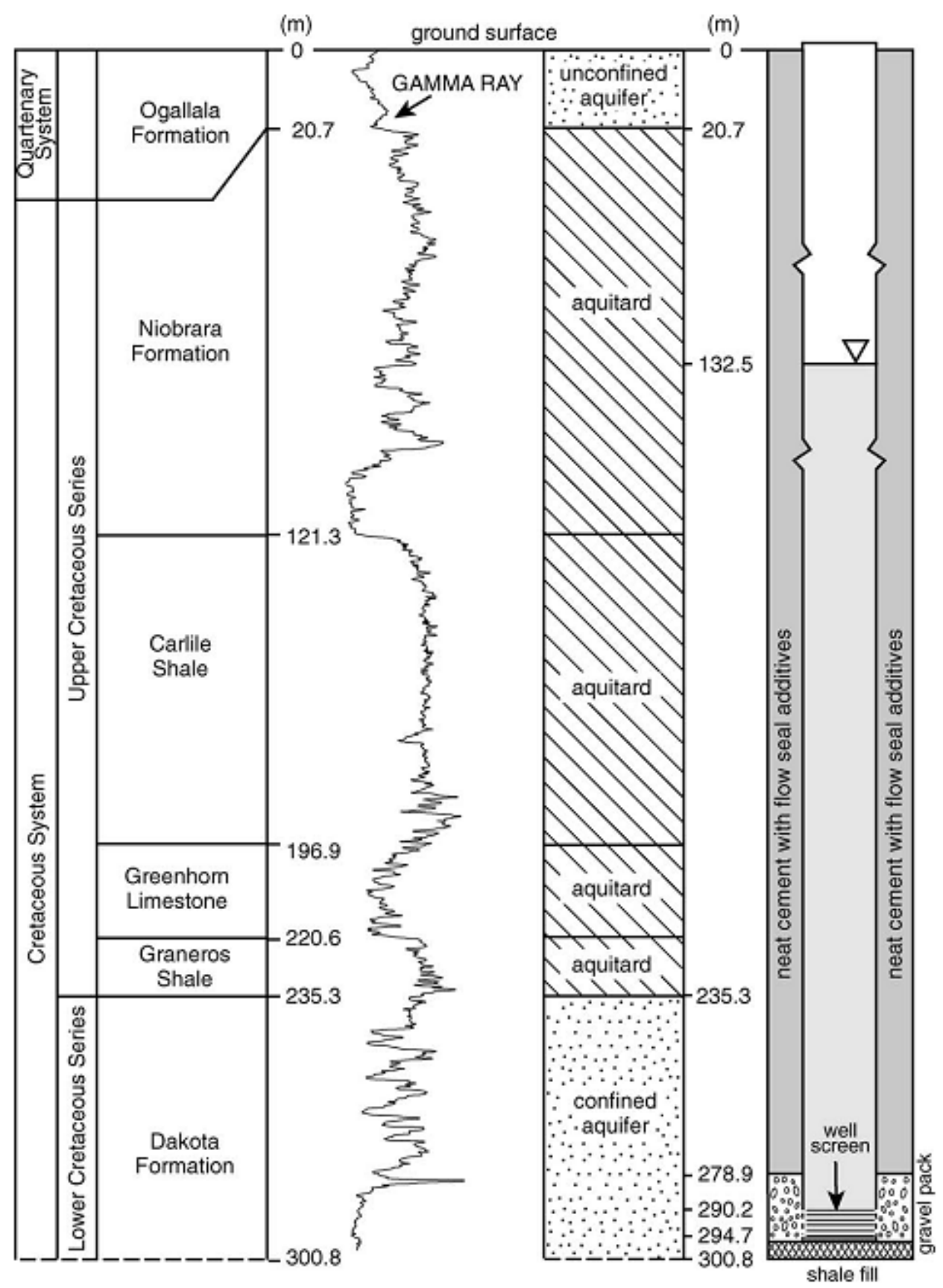

Figure 2. Subsurface stratigraphy and well construction of the WaKeeney well. 
The Niobrara Chalk of Late Cretaceous age crops out along the river valleys and their tributaries and consists chiefly of alternating beds of light-gray chalk, chalky limestone, and chalky shale [Hodson, 1965]. The beds of shaly chalk are relatively impermeable and water is transmitted chiefly through joints and fractures only locally and in small quantities. The Niobrara Chalk is divided into two members, the Fort Hays Limestone below and the Smoky Hill Chalk above. The Carlile shale of Late Cretaceous age consists of the Fairport Chalk Member (lowermost), the Blue Hill Shale Member, and the Codell Sandstone Member (uppermost), which locally yields small amounts of water to wells. The Greenhorn Limestone consists principally of alternating thin beds of chalky limestone and marl, which are both relatively impervious and do not yield water to wells. Underlying the Greenhorn Limestone is the Graneros Shale, which consists chiefly of dark-gray to black noncalcareous shale and yields no water to wells [Hodson, 1965].

Finally, the Dakota Formation of Early Cretaceous age consists chiefly of varicolored clay containing irregular, lenticular beds of siltstone and sandstone and yields quantities of water sufficient only for domestic or stock supplies. The depth to the Dakota Formation around the WaKeeney site is typically $235 \mathrm{~m}$ or greater below ground surface, whereas the Dakota static water level is approximately $132.4 \mathrm{~m}$ below ground surface. The sandstone lenses of the Dakota Formation have a significant degree of confinement from the thick overlying relatively impervious shaly and chalky formations and adjacent Dakota siltstones. These thick confining layers indicate minimal downward recharge. The WaKeeney well itself is screened only within the Dakota Formation (Fig. 2), providing a good experimental framework to check for any loading effects at depth.

\section{Rainfall and atmospheric loading effects}

A preliminary period of monitoring the open-well water levels established a value of $b=$ 0.62 for the local static confined barometric efficiency of the Dakota formation based on four different estimation techniques described in Sophocleous et al., 2004. The well was sealed from atmospheric pressure variation on June 23, 2004 and air pressure within the well was monitored to confirm the ongoing integrity of the seal. Well water levels were recorded hourly using a field-calibrated mini-TROLL data logging probe. Hourly barometric pressure data from a Digiquartz barometer were obtained from the U. S. National Weather Service Hill City weather station, some $30 \mathrm{~km}$ north of the site. Hourly rainfall data were obtained from a USGS stream-gaging station at the Saline River approximately $8 \mathrm{~km}$ northeast of the site (Fig. 1). We recognize that better estimates of barometric pressures and precipitation could be obtained by instrumenting the study site with appropriate sensors. However, due to the impromptu, proof-of-concept nature of this experimental study, plus the general similarity of the surrounding physiographic/climatic region to our study site, such refinement of study results was not considered critical. 
Fortuitously, a significant rainfall event of $8.6 \mathrm{~cm}$ was recorded at the Saline River gage on July 1 and the well data were downloaded on July 13, 2004. Figure 3a shows the well water levels as recorded, together with the atmospheric pressure record. Transmission of atmospheric loading through the confining layers to the Dakota aquifer is evident in the positive correlation between atmospheric pressure and well water levels - opposite to the usual inverse relation for open wells. Figure $3 b$ shows the cumulative rainfall, recorded at the USGS Saline River station (Fig. 1), during parts of June and July, 2004 with a pronounced step signifying the July $1^{\text {st }}$ rainfall event mentioned earlier, together with the measured and corrected-for-barometric-pressure water level (which much more clearly shows the loading impact of the July $1^{\text {st }}$ rainfall event). Correcting for atmospheric effects reveals both an evident strong earth tide signal consistent with a solar-lunar cycle and an upward displacement of water level synchronous with the July $1^{\text {st }}$ rainfall event and consistent with a rainfall loading effect (Fig. 3c). It may be possible to deduce additional aquifer properties from the earth tide data following Rojstaczer and Agnew (1989) but this was not attempted here. The increasing step function in Fig. $3 \mathrm{c}$ is the predicted water level from the rainfall loading, obtained by multiplying the cumulative rainfall by the 0.38 loading coefficient value (obtained as $1-b$ ).

The predicted well water level rise from rainfall loading is slightly less than the observed rise. However, the match is still quite good when taking into account some possible residual noise effect from earth tides. Also, the July 1 site rainfall could have been greater than recorded at the USGS Saline River monitoring station. In fact, the total rainfall on July $1^{\text {st }}, 2004$ from a manual climatic station in the town of WaKeeney (recording daily totals) was $10.7 \mathrm{~cm}$, indicating that the large thunderstorm of July 1 was spatially variable. The predicted water level from the same June-July 2004 period rainfall loading, based on the town of WaKeeney station, is also plotted in Fig. 3c, assuming that all daily rainfall occurred during the hour following midnight for each 24-hour period, with improved results.

Figure 3d shows the same plots as in Fig. 3c but with the earth tide effect largely removed after using a wavelet filter, which was applied subsequently to barometric correction. The plots of predicted rainfall loading in Figs. 3c and 3d are shown displaced vertically to match the approximate start point of the July $1^{\text {st }}$ water level rise because there is some degree of background trend of rising water levels independent of rainfall effects. Although the rain event loading signal is clear, there is no general implication in this case that the confined aquifer is behaving at all times as a geological weighing lysimeter. Confirmation of such behavior would require replication of observations over at least two vertically separated confined aquifers (Bardsley and Campbell, 2000). Therefore some form of slow recharge at depth cannot be excluded as a possible explanation for the overall rising trend in water pressure. 
Figure 3. Results of the sealing experiment: (a) atmospheric pressure and depth to water-level fluctuations; (b) original and barometrically corrected water levels (expressed as height of water column above the location of pressure transducer in the well), and cumulative rainfall (USGS Saline River station); (c) barometrically corrected and predicted water levels from rainfall loading from two climatic stations; (d) same as (c) but with wavelet-smoothed water level, applied subsequent to barometric correction.
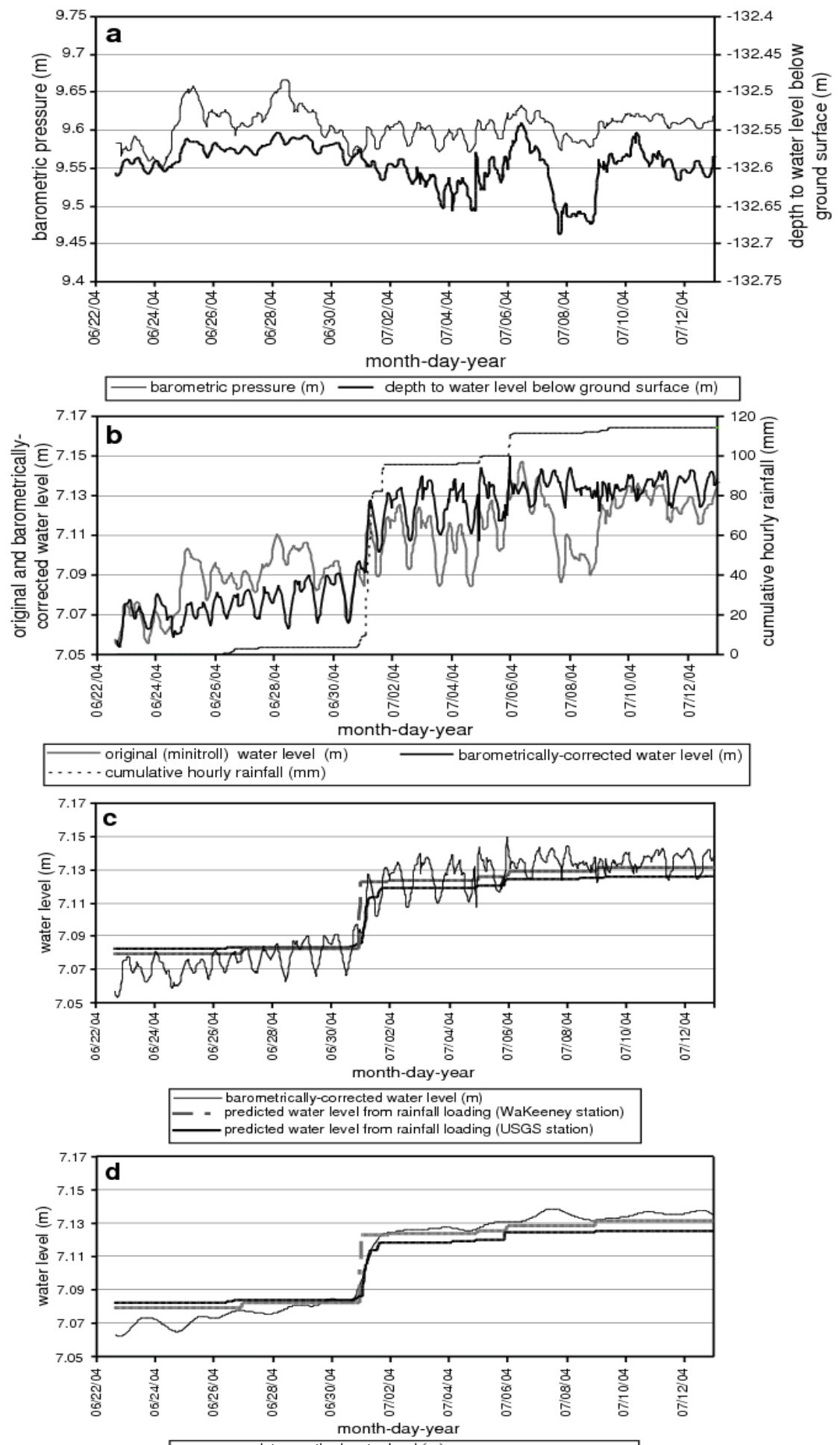

- - wavelet-smoothed water level (m) 


\section{Discussion and conclusion}

Although the detection of a rainfall loading signal at 300 meters depth may not be considered a large advance beyond the 240 meter depth reported by Bardsley and Campbell [2000], the important point here is that the additional depth increment does not appear to have imposed any reduction of clarity of the rainfall loading signal other than the nuisance effect of earth tides. This gives the possibility of future deployment of geological weighing lysimeters at considerable depth, perhaps as deep as a kilometer or more below ground surface. In this regard we are hopeful that our claim for a record 300 meter precipitation detection depth may be updated by our seismological colleagues inspecting their archives of deep monitoring well networks. Any loading signal here is most likely to be evident in monitoring networks where low relief and permeable soil allow temporary storage of rainfall rather than the water being exported quickly as stream discharge. The low relief at the WaKeeney site was a distinct advantage because the rainwater evidently remained in the local subsurface for at least 10 days subsequent to the July 1 event, giving rise to a clear step function signal in the well water levels after barometric correction.

We note that only a very weak rainfall signal was detected at 500 meters by Igarashi and Wakita [1991]. However, it may be that that Japanese site was not suitable for retention of the rainfall load. Also, those authors raised the possibility that their monitored aquifer might not be tightly confined.

If the way is in fact opened for geological weighing lysimeters at depth, then the possibility arises for hydrological monitoring of significant land areas and obtaining areaintegrated evaporation estimates. Considering the monitored area to be a circle centered on a deep observation well, the larger the circle radius the smaller the relative contributions to total storage change from near-surface lateral groundwater transfers across the circle perimeter. A sufficiently large "weighed" surface area will therefore have water storage change dominated by inputs from precipitation and outputs by way of river discharge and evaporation. River discharge and precipitation can be independently recorded and storage change measured directly from the deep geological weighing lysimeter. Area-integrated evaporation would then be deduced as the one remaining unknown in the area water balance. This is analogous to a standard drainage basin water balance but with the important difference that the storage change now is directly measured, allowing evaporation losses to be deduced over much smaller time periods. 


\section{Acknowledgements}

We would like to thank Mr. Larry Connor, the owner of the WaKeeney site for allowing us access to his property, and the following individuals at the Kansas Geological Survey: Student Research Assistant Brett Engard for data processing help, Allen MacFarlane for loaning us the minitroll datalogger used to measure the water levels reported here as well as for sharing his geophysical logging expertise, and Jim Butler for making available the levelogger used in the sealing experiment.

\section{References}

Bardsley, W.E., and D.I. Campbell, 1994. A new method for measuring near-surface moisture budgets in hydrological systems. Journal of Hydrology 154(1-4), 245-254.

Bardsley, W.E., and D.I. Campbell, 2000. Natural geological weighing lysimeters: calibration tools for satellite and ground surface gravity monitoring of subsurface water mass change. Natural Resources Research 9(2), 147-156.

Hodson, W.G., 1965. Geology and groundwater resources of Trego County, Kansas. Kansas Geol. Survey, Bulletin 174, Lawrence, Kansas, 80 p.

Igarashi, G., and H. Wakita, 1991. Tidal responses and earthquake-related changes in the water level of deep wells. Journal of Geophysical Research 96 B3, 4269-4278.

Jacob, C.E., 1940. On the flow of water in an artesian aquifer. Eos Transactions of the American Geophysical Union 21, 574-586.

Matsumoto, N, and E. A. Roeloffs, 2003. Hydrological response to earthquakes in the Haibara well, central Japan - II. Possible mechanism inferred from time-varying hydraulic properties. Geophysical Journal International 155, 899-913.

Pagiatakis, S.D., 1990. The response of a realistic Earth to ocean tide loading. Geophysical Journal International 103(2), 541-560. 
Roeloffs E. A., 1996. Poroelastic techniques in the study of earthquake-related hydrologic phenomena. Advances in Geophysics 37, 135-195.

Rojstaczer, S.A., 1988. Determination of fluid flow properties from the response of water levels in wells to atmospheric loading. Water Resources Research 24,1927-1938.

Rojstaczer, S.A., and D.C. Agnew, 1989. The influence of formation material properties on the response of water levels in wells to earth tides and atmospheric loading. Journal of Geophysical Research 94 B9, 12403-12411.

Sophocleous, M.A., W.E. Bardsley, J. Healey, and B. Rengard, 2004. Can precipitation loading be detected at 300-meter depth or greater? Kansas Geological Survey, Open-File Report 2004-46, Lawrence, Kansas, 19 p.

van der Kamp, G., and H. Maathuis, 1991. Annual fluctuations of groundwater levels due to loading by surface moisture. Journal of Hydrology 127, 137-152.

van der Kamp, G., and R. Schmidt, 1997. Monitoring of total soil moisture on a scale of hectares using groundwater piezometers. Geophysical Research Letters 24(6), 719-722. 